\title{
Case Report: Concomitant coronary stent and femoral artery thrombosis in the setting of heparin-induced
}

\section{thrombocytopenia [version 1; peer review: 2 approved]}

\author{
Mejdi Ben Messaoud (D1, Mezri Maatouk2, Mohamed Mehdi Boussaada1, \\ Marouane Mahjoub (D1) Walid Mnari², Habib Gamra1 \\ ${ }^{1}$ Cardiology A Department, Fattouma Bourguiba University Hospital, Monastir, Monastir, Monastir, 5000, Tunisia \\ ${ }^{2}$ Radiology Department, Fattouma Bourguiba University Hospital, Monastir, Monastir, Monastir, 5000, Tunisia
}

V1 First published: 15 May 2019, 8:667

https://doi.org/10.12688/f1000research.19041.1

Latest published: 15 May 2019, 8:667

https://doi.org/10.12688/f1000research.19041.1

\section{Abstract}

Heparin induced thrombocytopenia (HIT) is a rare but potentially life threatening adverse drug reaction. We report an unusual case of concomitant subacute coronary stent and femoral artery thrombosis secondary to HIT. In the current era of extensive growth of heparin use and percutaneous coronary interventions, it's important for clinicians to remember that such complication might occur and should be prevented.

\section{Keywords}

Key words: heparin; thrombocytopenia; thrombosis; coronary artery; stent; myocardial infarction; femoral artery; coronary angioplasty; thrombectomy

\begin{abstract}
Open Peer Review
Approval Status

1

2

version 1

15 May 2019

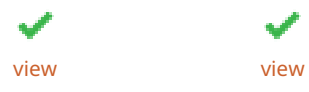

1. Batric Popovic, Centre Hospitalier

Universitaire Brabois, Nancy, France

2. Marouane Boukhris, Centre Hospitalier de

I'Université de Montréal, Quebec, Canada

Any reports and responses or comments on the article can be found at the end of the article.
\end{abstract}

Corresponding author: Mejdi Ben Messaoud (mejdibenmessaoud@yahoo.fr)

Author roles: Ben Messaoud M: Writing - Original Draft Preparation; Maatouk M: Conceptualization; Boussaada MM: Formal Analysis; Mahjoub M: Validation; Mnari W: Conceptualization; Gamra H: Writing - Review \& Editing

Competing interests: No competing interests were disclosed.

Grant information: The author(s) declared that no grants were involved in supporting this work.

Copyright: ( $\subset 2019$ Ben Messaoud $\mathrm{M}$ et al. This is an open access article distributed under the terms of the Creative Commons Attribution License, which permits unrestricted use, distribution, and reproduction in any medium, provided the original work is properly cited.

How to cite this article: Ben Messaoud M, Maatouk M, Boussaada MM et al. Case Report: Concomitant coronary stent and femoral artery thrombosis in the setting of heparin-induced thrombocytopenia [version 1; peer review: 2 approved] F1000Research 2019, 8:667 https://doi.org/10.12688/f1000research.19041.1

First published: 15 May 2019, 8:667 https://doi.org/10.12688/f1000research.19041.1 


\section{Introduction}

Heparin is a commonly used anticoagulant for hospitalized patients, but its use can lead to devastating complications, such as heparin-induced thrombocytopenia (HIT) ${ }^{1}$. We report an unusual case of concomitant subacute coronary stent and femoral artery thrombosis in the setting of HIT. This case highlights the importance of considering HIT as a cause of coronary or arterial thrombosis few days after heparin exposure.

\section{Case report}

A 66-year-old male patient, with a history of smoking (30 pack-years) and no known medical or surgical history, was admitted in our department for a spontaneously resolved inferior ST elevation myocardial infarction (STEMI). The intra-hospital treatment included enoxaparin $0.6 \mathrm{ml}$ twice a day, clopidogrel $75 \mathrm{mg}$ once a day, aspirin $100 \mathrm{mg}$ once a day, bisoprolol $2.5 \mathrm{mg}$ once a day and atorvastatin $40 \mathrm{mg}$ once a day. The coronary angiogram (performed at day 3 through the right radial artery) showed a severe thrombotic lesion of the distal circumflex. The patient underwent an ad-hoc successful angioplasty of the circumflex with a drug eluting (everolimus) stent. Initial laboratory tests at admission were normal except elevated troponin. Echocardiography showed a $65 \%$ left ventricular ejection fraction. The patient was discharged after 5 days of anticoagulation by low molecular weight heparin (enoxaparin). Laboratory tests were not controlled during the hospitalization. The discharge treatment included clopidogrel $75 \mathrm{mg}$ once a day, aspirin $100 \mathrm{mg}$ once a day, bisoprolol $2.5 \mathrm{mg}$ once a day and atorvastatin $40 \mathrm{mg}$ once a day.

One week later, the patient was referred again to our department for both chest and right lower limb pain. The electrocardiogram showed an inferior STEMI and the physical exam of the right lower limb found ischemic signs with absence of the femoral pulse. There was no history of aspirin or clopidogrel discontinuation. An urgent coronary angiogram (performed through the left femoral artery) showed total thrombosis of the circumflex stent (Figure 1A). The patient underwent a successful primary angioplasty of the circumflex by simple balloon (Figure 1B). Urgent lower limb contrast-enhanced computed tomography was performed immediately after the angioplasty, revealing total acute thrombosis of the right common femoral
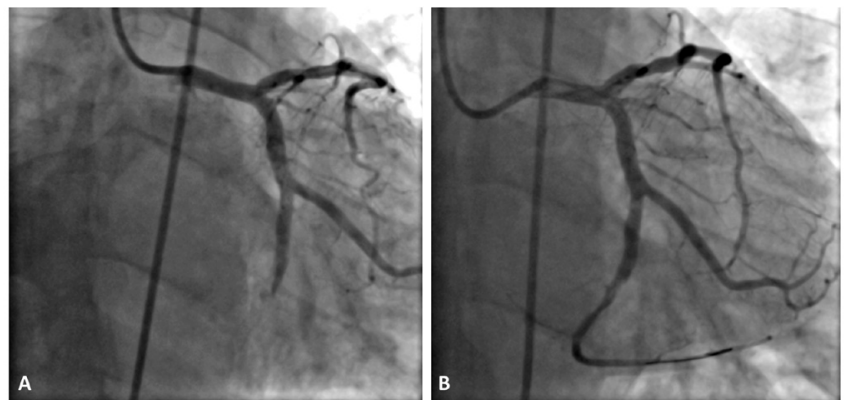

Figure 1. Coronary angiogram images. (A) The intra-stent thrombosis of the circumflex coronary artery. (B) The final result after successful angioplasty of the circumflex coronary artery. artery (Figure 2A, B). The patient underwent an urgent successful thrombectomy with Fogarty catheter. Immediate evolution was favorable with total regression of coronary and right lower limb ischemic signs. Laboratory tests showed a marked fall in the platelet count $(68,000 / \mathrm{L})$ which was normal $(364,000 / \mathrm{L})$ in the previous hospitalization. A diagnosis of concomitant coronary stent and femoral artery thrombosis due to HIT was strongly suspected (4T score $=8$ ). Our therapeutic strategy was immediate discontinuation of low molecular weight heparin (enoxaparin), aspirin and clopidogrel with strict daily control of platelet count. During this period, no alternative anticoagulation was initiated because of the unavailability of direct thrombin inhibitors in our center. Anticoagulation with a vitamin $\mathrm{K}$ antagonist (acenocoumarol $4 \mathrm{mg}$ once a day) and dual antiplatelet therapy with aspirin $100 \mathrm{mg}$ once a day and clopidogrel $75 \mathrm{mg}$ once a day were initiated at day 3 once platelet count had recovered. The in-hospital outcome was favorable and the patient was discharged after 15 days on acenocoumarol $4 \mathrm{mg}$ once a day, aspirin $100 \mathrm{mg}$ once a day and clopidogrel $75 \mathrm{mg}$ once a day. The 3-month follow-up, with controlled blood tests and lower limb contrast-enhanced computed tomography showing total reperfusion of the right femoral artery (Figure 2C), was unremarkable.

\section{Discussion}

HIT is defined as a sudden fall in the platelet count (e.g. $<100,000$ per $\mathrm{L}$ or $>50 \%$ drop from baseline) a few days after heparin use. Its incidence ranges from $<1 \%$ to $7 \%$ depending on the heparin type (more than 10 times higher with unfractionated heparin compared to low-molecular-weight heparin), duration of heparin exposure and patient population ${ }^{1}$. There are two types of HIT, with type I HIT the most common form. Type 1 HIT is due to the direct effect of heparin on platelets and may manifest as only a slight decrease in platelet count, mostly within 2 days of

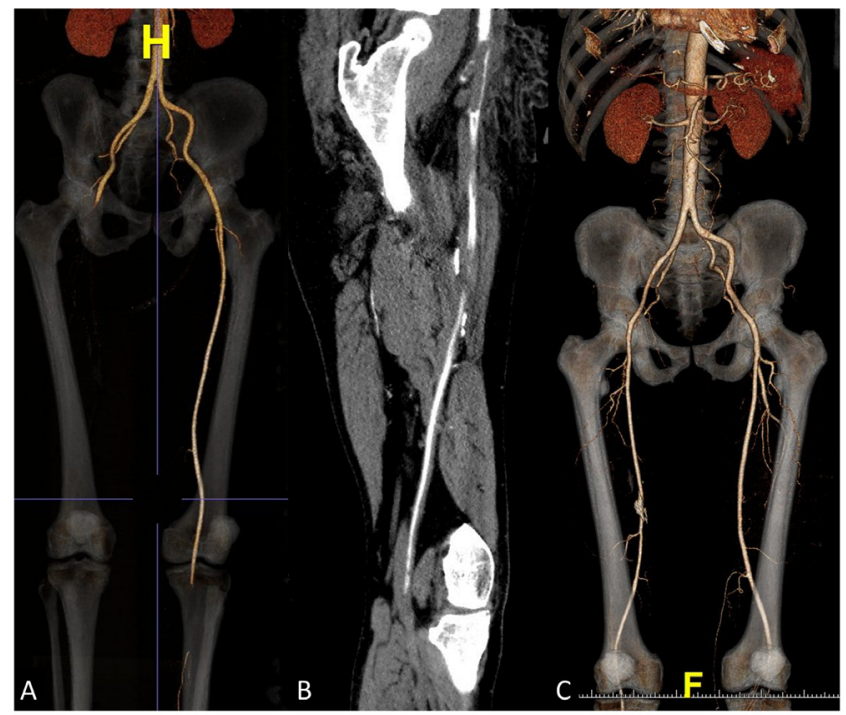

Figure 2. Lower limb contrast enhanced computed tomography images. (A, B) show the thrombotic occlusion of the right common femoral artery. (C) Reperfusion of the right femoral artery after thrombectomy. 
commencing heparin. Type II HIT is secondary to the formation of antibodies against the heparin-platelet factor 4 complex, resulting in $50 \%$ of cases in thrombotic events, mostly in veins, within 5 to 14 days. Coronary artery thrombosis secondary to HIT is very rare and usually occurs in the setting of coronary stents or bypass grafts ${ }^{2}$. However, the concomitant occurrence of coronary stent and other arterial site thrombosis secondary to HIT is very rare and few cases have been reported in the literature ${ }^{3}$. The use of scoring systems such as the "4T score" is helpful in assessing the pretest probability of $\mathrm{HIT}^{4}$. Platelet factor 4-heparin antibody tests should be ordered only if the diagnosis of HIT is strongly suggested by clinical features ${ }^{5}$.

Treatment of HIT requires immediate discontinuation of all heparin products and initiation of alternative therapeutic dose anticoagulation, including direct thrombin inhibitors (argotraban, bivalirudin, fondaparinux, danaparoid) or direct oral anticoagulants (apixaban or rivaroxaban or dabigatran) ${ }^{6}$. The decision to continue antiplatelet therapy during treatment with a non-heparin anticoagulant may be influenced by the risk of vascular events and bleeding. Routine platelet transfusion is not recommended for patients with acute HIT and thrombosis or average bleeding risk, but it may be an option for patients with active bleeding or at high bleeding risk. In the acute phase of HIT with life-threatening thrombosis, bivalirudin (or argatroban if bivalirudin is unavailable) is the best option for alternative anticoagulation therapy ${ }^{7}$. Primary angioplasty and thrombectomy with Fogarty catheter should be recommended in the setting of life-threatening thrombosis with STEMI or acute limb thromboembolism ${ }^{8}$. Oral anticoagulation is required for at least 3 months, preferably with direct oral anticoagulant, which can be initiated at the first day. Warfarin is the most highly recommended vitamin $\mathrm{K}$ antagonist when indicated, and should not be given until platelets have substantially recovered (e.g. usually to at least 150000 per L) ${ }^{7}$. In our case, acenocoumarol was the sole available alternative anticoagulation therapy. It was initiated at day 3 after platelet count recovery and was continued for 3 months.

\section{Conclusion}

Concomitant coronary and femoral artery thrombosis due to HIT is a rare life-threatening complication of heparin therapy. The present case highlights the importance of considering such diagnosis among patients with prior heparin exposure. Prompt identification and management of this disorder is critically important to avoid devastating complications. To prevent such events, strict control of platelet count during heparin therapy is of paramount importance.

\section{Data availability}

All data underlying the results are available as part of the article and no additional source data are required.

\section{Consent}

Written informed consent for publication of their clinical details was obtained from the patient.

\section{Grant information}

The author(s) declared that no grants were involved in supporting this work
1. Martel N, Lee J, Wells PS: Risk for heparin-induced thrombocytopenia with unfractionated and low-molecular-weight heparin thromboprophylaxis: a metaanalysis. Blood. 2005; 106(8): 2710-5. PubMed Abstract | Publisher Full Text

2. Shin HW, Yoon HJ, Choi SW, et al.: Acute Stent Thrombosis and Heparin Induced Thrombocytopenia in a Patient With ST-Segment Elevation Myocardial Infarction. Korean Circ J. 2012; 42(9): 646-9. PubMed Abstract | Publisher Full Text | Free Full Text

3. Suzuki H, Tsunematsu T, Takahashi $\mathrm{H}$, et al:: A case of heparin-induced thrombocytopenia with subacute stent thrombosis, multiple cerebral infarction, and acute limb ischemia. J Cardiol Cases. 2017; 15(5): 145-149. PubMed Abstract | Publisher Full Text | Free Full Text

4. Warkentin TE: Think of HIT. Hematology Am Soc Hematol Educ Program. 2006; 408-14.

PubMed Abstract | Publisher Full Text
5. Greinacher A: CLINICAL PRACTICE. Heparin-Induced Thrombocytopenia. N Engl J Med. 2015; 373(3): 252-61. PubMed Abstract | Publisher Full Text

6. Warkentin TE, Pai M, Linkins LA: Direct oral anticoagulants for treatment of HIT: update of Hamilton experience and literature review. Blood. 2017; 130(9): 1104-1113.

PubMed Abstract | Publisher Full Text

7. Cuker A, Arepally GM, Chong BH, et al:: American Society of Hematology 2018 guidelines for management of venous thromboembolism: heparin-induced thrombocytopenia. Blood Adv. 2018; 2(22): 3360-3392. PubMed Abstract | Publisher Full Text | Free Full Text

8. Anderson JL, Morrow DA: Acute Myocardial Infarction. N Engl J Med. 2017; 376(21): 2053-2064.

PubMed Abstract | Publisher Full Text 


\section{Open Peer Review}

\section{Current Peer Review Status:}

\section{Version 1}

Reviewer Report 04 July 2019

https://doi.org/10.5256/f1000research.20868.r49698

(C) 2019 Boukhris M. This is an open access peer review report distributed under the terms of the Creative Commons Attribution License, which permits unrestricted use, distribution, and reproduction in any medium, provided the original work is properly cited.

\section{Marouane Boukhris}

Centre Hospitalier de l'Université de Montréal, Quebec, Canada

In this current manuscript, the authors reported the case of a STEMI patient who suffered from heparin-induced thrombocytopenia resulting not only in stent thrombosis but also in femoral artery thrombotic occlusion. Overall, the paper is well written and of interest for the reader. It is suitable for indexing in its actual version.

Is the background of the case's history and progression described in sufficient detail? Yes

Are enough details provided of any physical examination and diagnostic tests, treatment given and outcomes?

Yes

Is sufficient discussion included of the importance of the findings and their relevance to future understanding of disease processes, diagnosis or treatment?

Yes

Is the case presented with sufficient detail to be useful for other practitioners? Yes

Competing Interests: No competing interests were disclosed.

Reviewer Expertise: Interventional cardiology

I confirm that I have read this submission and believe that I have an appropriate level of expertise to confirm that it is of an acceptable scientific standard.

Reviewer Report 04 June 2019 


\section{https://doi.org/10.5256/f1000research.20868.r48571}

(C) 2019 Popovic B. This is an open access peer review report distributed under the terms of the Creative Commons Attribution License, which permits unrestricted use, distribution, and reproduction in any medium, provided the original work is properly cited.

\section{Batric Popovic}

Department of Cardiology, Centre Hospitalier Universitaire Brabois, Nancy, France

\section{Comments:}

I read with great interest the report written by Mejdi Ben Messaoud et al. about an unusual case of concomitant subacute coronary stent and femoral artery thrombosis secondary to heparin induced thrombocytopenia. There had been previous reported cases of HIT causing coronary thrombus formation but not with concomitant extracoronary thrombotic events.

The authors confirm that a heparin therapy needs a platelet count at least 2 / week which is a wellknown recommendation. I think that authors should also emphasize that a prolonged and unnecessary anticoagulation after percutaneous coronary intervention may be deleterious. Indeed, different studies reported that in elective PCI or after primary angioplasty after myocardial infarction, the anti coagulation should be early discontinued.

This report needs several minor modifications as follows:

\section{Abstract:}

"In the current era of extensive growth of heparin use and percutaneous coronary interventions, it's important for clinicians to remember that such complication might occur and should be prevented."

This sentence should be modified: PCI required perprocedural anticoagulation but dose and duration of anticoagulation have been decreased last decade. (See: Montalescot STEEPLE investigators and Futura/OASIS 8).

\section{Case report:}

"A 66-year-old male patient, with a history of smoking (30 pack-years) and no known medical or surgical history:". 30 pack years should be deleted and "no known": means without?

Echocardiography showed a $65 \%$ left ventricular ejection fraction. The authors should specify the presence or not of an intra cardiac mass. Indeed, one of the most frequent underlying cardiac diseases concomitant coronary and extra coronary acute thrombotic events is intracardiac mass/tumor.

The in-hospital outcome was favorable and the patient was discharged after 15 days on acenocoumarol $4 \mathrm{mg}$ once a day, aspirin $100 \mathrm{mg}$ once a day and clopidogrel $75 \mathrm{mg}$ once a day. Indicate the duration of this antithrombotic strategy in this paragraph and not in the discussion. 
“The 3-month follow-up, with controlled blood tests and lower limb contrast-enhanced computed tomography showing total reperfusion of the right femoral artery ,was unremarkable." The sentence may be modify: "At 3 month follow up, no recurrent thrombotic events occurred, controlled blood tests were normalized and low limb contrast-enhanced computed tomography completely reperfused."

Is the background of the case's history and progression described in sufficient detail? Yes

Are enough details provided of any physical examination and diagnostic tests, treatment given and outcomes?

Yes

Is sufficient discussion included of the importance of the findings and their relevance to future understanding of disease processes, diagnosis or treatment?

Partly

Is the case presented with sufficient detail to be useful for other practitioners?

Yes

Competing Interests: No competing interests were disclosed.

Reviewer Expertise: Thrombotic disorders and interventional cardiology

I confirm that I have read this submission and believe that I have an appropriate level of expertise to confirm that it is of an acceptable scientific standard.

The benefits of publishing with F1000Research:

- Your article is published within days, with no editorial bias

- You can publish traditional articles, null/negative results, case reports, data notes and more

- The peer review process is transparent and collaborative

- Your article is indexed in PubMed after passing peer review

- Dedicated customer support at every stage

For pre-submission enquiries, contact research@f1000.com

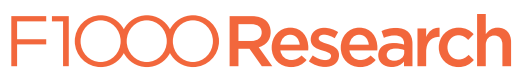

